\title{
Agmatine, a Bioactive Metabolite of Arginine Production, Degradation, and Functional Effects in the Kidney of the Rat
}

\author{
Mark J. Lortie, William F. Novotny, Orjan W. Peterson, Volker Vallon, Kirsten Malvey, Margarida Mendonca, Joseph Satriano, \\ Paul Insel, Scott C. Thomson, and Roland C. Blantz \\ Divisions of Nephrology-Hypertension and Hematology-Oncology, Departments of Medicine, Pharmacology and Bioengineering \\ Institute, University of California, San Diego School of Medicine, La Jolla, California 92093; and Veterans Affairs Medical Center, \\ San Diego, California 92161
}

\begin{abstract}
Until recently, conversion of arginine to agmatine by arginine decarboxylase (ADC) was considered important only in plants and bacteria. In the following, we demonstrate ADC activity in the membrane-enriched fraction of brain, liver, and kidney cortex and medulla by radiochemical assay. Diamine oxidase, an enzyme shown here to metabolize agmatine, was localized by immunohistochemistry in kidney glomeruli and other nonrenal cells. Production of labeled agmatine, citrulline, and ornithine from $\left[{ }^{3} \mathrm{H}\right]$ arginine was demonstrated and endogenous agmatine levels $\left(10^{-6} \mathrm{M}\right)$ in plasma ultrafiltrate and kidney were measured by HPLC. Microperfusion of agmatine into renal interstitium and into the urinary space of surface glomeruli of Wistar-Frömter rats produced reversible increases in nephron filtration rate (SNGFR) and absolute proximal reabsorption (APR). Renal denervation did not alter SNGFR effects but prevented APR changes. Yohimbine (an $\alpha_{2}$ antagonist) microperfusion into the urinary space produced opposite effects to that of agmatine. Microperfusion of urinary space with BU-224 $(\mu M)$, a synthetic imidazoline ${ }_{2}\left(I_{2}\right)$ agonist, duplicated agmatine effects on SNGFR but not APR whereas an $I_{1}$ agonist had no effect. Agmatine effects on SNGFR and APR are not only dissociable but appear to be mediated by different mechanisms. The production and degradation of this biologically active substance derived from arginine constitutes a novel endogenous regulatory system in the kidney. (J. Clin. Invest. 1996. 97:413-420.) Key words: agmatine • arginine decarboxylase $\bullet$ diamine oxidase $\bullet$ kidney $\bullet$ glomerular filtration • tubular reabsorption
\end{abstract}

\section{Introduction}

Arginine is an amino acid critical to normal growth and multiple physiologic processes. Arginine concentration in extracellular fluid is maintained at $100-200 \mu \mathrm{M}$ and is regulated by $(a)$ GI absorption, $(b)$ conversion to ornithine by the urea cycle,

A portion of this work was presented at the annual meeting of the American Society of Nephrology in Orlando, FL on 26-29 October 1994. Address correspondence to Dr. M. Lortie, Nephrology Research, VAMC (151), 3350 La Jolla Village Drive, San Diego, CA 92161. Phone: 619-552-8585 ext. 3473; FAX: ext. 2267, mlortie@ucsd.edu

Received for publication 13 March 1995 and accepted in revised form 26 October 1995

J. Clin. Invest.

(C) The American Society for Clinical Investigation, Inc.

0021-9738/96/01/413/08 \$2.00

Volume 97, Number 2, January 1996, 413-420 and $(c)$ synthesis from citrulline in the kidney $(1,2)$. The metabolic fate of this amino acid in cells is less well defined, but products derived from arginine are known to be important bioactive compounds. An enormous interest has focused upon the physiologic and pathophysiologic roles of nitric oxide (NO) generated from arginine by NO synthase (1-3). It is now evident that other bioactive compounds are generated from arginine $(4,5)$. The enzyme arginine decarboxylase (ADC) ${ }^{1}$ was previously considered important primarily in bacteria and plants (6-8). However, recent publications have suggested that ADC is present in mammalian systems (9-12).

Earlier work with plants has shown that agmatine is avidly degraded by the enzyme, diamine oxidase (DAO) which converts agmatine to guanidino-butylaldehyde (Fig. 1) (13). Novotny et al. isolated DAO and found that the amino acid sequence was identical to that of "amiloride binding protein" (14). Amiloride and amiloride analogues significantly inhibit DAO by binding at the active site of the enzyme. It is of interest that aminoguanidine, a structurally simplified version of agmatine known to inhibit inducible NOS (15-16), is also a potent inhibitor of DAO (17).

Investigators have pursued identification of the endogenous clonidine displacing substance (CDS) from brain and lung extract. Clonidine and other centrally acting hypotensive agents such as guanabenz are known to exert physiologic effects via $\alpha_{2}$-adrenergic and/or imidazole type receptors (18). Imidazoline receptors have been defined $\left(\mathrm{I}_{1}\right.$ and $\left.\mathrm{I}_{2}\right)$ in the central nervous system and other tissues such as the basolateral aspect of proximal tubules (19). Li et al. demonstrated that a significant concentration of agmatine $(0.2-0.4 \mu \mathrm{g} / \mathrm{gram})$ is present in brain and that this compound was a ligand for both imidazoline and $\alpha_{2}$ adrenergic receptors (1).

Others have shown that agmatine infusion into the cerebral ventricles increases blood pressure while systemic infusion decreases blood pressure (20). Agmatine is purported to stimulate release of norepinephrine in the central nervous system and in chromaffin cells, a system which does not express $\alpha_{2}$ adrenergic receptors. Other investigators have not observed agmatine induced norepinephrine release in the chromaffin cell system but have suggested that agmatine is a nicotinic antagonist in chromaffin cells (unpublished observations and reference 21).

Agmatine is a biologically active substance, but the mode and sites of action have not been fully defined. The current studies provide evidence that this alternate arginine metabolic pathway is of physiological importance to renal function. The

1. Abbreviations used in this paper: ADC, arginine decarboxylase; APR, absolute proximal reabsorption; DAO, diamine oxidase; I, imidazoline; SNGFR, single nephron glomerular filtration rate. 


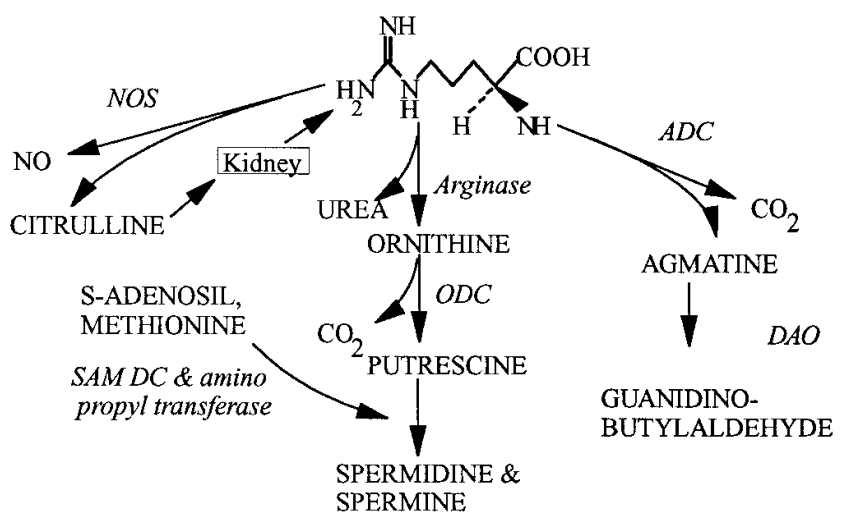

Figure 1. The major metabolic pathways for arginine are depicted and involve primarily the conversion of arginine to citrulline by NOS, conversion of arginine to ornithine by arginase and, as described in the current study, conversion of arginine to agmatine by arginine decarboxylase (ADC). Downstream products are also depicted.

aims are as follows: (a) Demonstrate ADC and DAO in various tissues. (b) Demonstrate agmatine production and measure endogenous levels in renal tissue. (c) Determine physiological effects of the ADC/agmatine system on glomerular and proximal tubule function. (d) Characterize receptor types involved in the renal effects of agmatine using selective adrenergic and/or imidazoline agonists and antagonists.

\section{Methods}

ADC activity and location in mammalian tissue. Three female Wistar rats (300 grams) were anesthetized and exsanguinated before collecting the brain, liver, heart, spleen, kidneys, and lungs. The kidneys were decapsulated and dissected in order to separate the cortex and medulla. The organs of each animal were individually weighed (after weighing the whole liver a potion was sectioned and weighed for assay) homogenized in $5 \mathrm{ml}$ cold buffer DME plus pyridoxal phosphate (0.05 and $0.5 \mathrm{mM})$ with a Polytron at high speed in short bursts. Homogenates were centrifuged at low speed $\left(300 \mathrm{~g}, 4^{\circ} \mathrm{C}\right)$ for $15 \mathrm{~min}$ to remove large pieces and unbroken cells. The supernatant was then centrifuged for $40 \mathrm{~min}$ at $15,000 \mathrm{~g}\left(4^{\circ} \mathrm{C}\right)$ to isolate a mitochondria enriched pellet that was resuspended in the buffer described above.

Radiolabeled $\mathrm{CO}_{2}$ generation from ${ }^{14} \mathrm{C}$ arginine (C-1-labeled, 50$60 \mathrm{mCi} / \mathrm{mmol}$; American Radiolabeled Chemicals, St. Louis, MO) was used as an index of ADC activity. Large bore test tubes, capped with rubber stoppers and fitted with a metabolic well (Kontes) containing $300 \mu \mathrm{l}$ of trapping agent (Solvall, Dupont), were used to incubate cell fractions at $37^{\circ} \mathrm{C}$. Cell fractions were incubated with $1.5 \times$ $10^{6} \mathrm{CPM}$ of $\left[{ }^{14} \mathrm{C}\right]$ arginine. Enzyme activity was terminated by injecting $40 \%$ TCA through the cap after $60 \mathrm{~min} .1 \mathrm{~h}$ of equilibration at room temperature ensured complete trapping of labeled $\mathrm{CO}_{2}$. Metabolic wells containing trapped ${ }^{14} \mathrm{CO}_{2}$ were carefully transferred to $6 \mathrm{ml}$ vials containing scintillation fluid for counting. ADC activity is expressed as CPM of $\mathrm{CO}_{2}$ generated in 60 min per gram wet tissue.

Polyclonal antibody immunostaining for DAO. Diamine oxidase, obtained from human placental tissue using the Baylin technique (23), were emulsified in complete Freund's adjuvant and injected subcutaneously into multiple sites over the back of one New Zealand White rabbit. 2 wk later another $50 \mu \mathrm{g}$ of diamine oxidase was emulsified in incomplete Freund's adjuvant and injected in equal doses into both thigh muscles. 2 wk later the rabbit was phlebotomized and the whole blood was allowed to clot for $2 \mathrm{~h}$ in a $37^{\circ} \mathrm{C}$ water bath. IgG was purified from serum using protein $G$ chromatography. The antidiamine oxidase $\mathrm{IgG}$ recognizes a single band in placental extract, cultured cells, and post heparin plasma, and is able to neutralize $>99 \%$ of the diamine oxidase activity in placental extract at dilutions of $1 / 100$.

Nonmalignant human tissues from autopsy specimens, and adult mouse tissues were embedded in methyl methacrylate, snap frozen, and stored at $-70^{\circ} \mathrm{C}$. $10-\mu \mathrm{m}$ frozen sections were cut, mounted, air dried, and stained immediately. Slides were first blocked with $0.1 \%$ goat serum in phosphate buffered saline (PBS), and then incubated with either pre-immune rabbit IgG or anti-diamine oxidase IgG. The secondary antibody used was an immunoperoxidase linked anti-rabbit $\mathrm{IgG}$, and color was developed using amino ethylcarbazole and $0.03 \% \mathrm{H}_{2} \mathrm{O}_{2}(22)$. The slides were then counterstained with hematoxylin, mounted, and examined.

Agmatine metabolism by DAO - effects of aminoguanidine. Pig kidney DAO was purified as described previously (13). $\mathrm{H}_{2} \mathrm{O}_{2}$ generated from agmatine by DAO was measured by fluorometric assay using horseradish peroxidase (HPO Type 2; Sigma Chemical Co., St. Louis, MO) and fluorogene-3-( $p$-hydroxyphenyl) proprionic acid (HPPA; Aldrich Chemical Co. Milwaukee, WI).

Reaction mixture consisted of $650 \mu$ l buffer $(0.02 \mathrm{M}$ Tris, $0.07 \mathrm{M}$ $\mathrm{NaCl}, \mathrm{pH} 8.9), 100 \mu \mathrm{l} \mathrm{HPPA}(7.5 \mathrm{mM}), 50 \mu \mathrm{l}$ HPO $(2 \mathrm{U} / \mathrm{ml}), 100 \mu \mathrm{l}$ purified DAO (diluted 1:10 in 0.05 M Tris, 0.022 Azide, $0.2 \mathrm{mg} / \mathrm{ml}$ BSA) and $100 \mu \mathrm{l}$ of buffer containing agmatine $(0-100 \mu \mathrm{M}$ final concentration). A standard curve for $\mathrm{H}_{2} \mathrm{O}_{2} \quad(0-50 \mu \mathrm{M}$ final concentration) was established concurrently. After $60 \mathrm{~min}$ at $37^{\circ} \mathrm{C}$, reaction was terminated with the addition of $100 \mu \mathrm{l}$ aminoguanidine (0.1 M; Eastman Kodak Co., Rochester, NY) a competitive inhibitor for DAO. We have previously established a $K_{\mathrm{i}}$ of $0.5 \mu \mathrm{M}$ for aminoguanidine against putrescine in an identical preparation. Also addition of aminoguanidine before agmatine completely eliminates $\mathrm{H}_{2} \mathrm{O}_{2}$ production. Fluorescence was measured within $60 \min$ (excitation $=320 \mathrm{~nm}$, emission $=404 \mathrm{~nm}$ ) and corrected values plotted against the standard curve for $\mathrm{H}_{2} \mathrm{O}_{2}$.

HPLC identification of arginine metabolites. Methods for separation and quantification of arginine, agmatine, ornithine and citrulline from bacteria by HPLC are well established (24). We have developed a method based on spectrophotometric assay following pre-column derivatization with $O$-phthalaldehyde. This method permits separation and detection of primary and secondary amines (including the polyamines). Fractionation of the eluate enabled us to isolate and quantify metabolites of labeled arginine.

After anesthesia and exsanguination, the cortex of both kidneys from a 250-gram female Frömter-Wistar rat where homogenized in $2 \mathrm{ml}$ of warm buffer (described above) $\left[{ }^{3} \mathrm{H}\right]$ arginine $\left(10^{6} \mathrm{CPM}, 91 \mathrm{Ci} / \mathrm{mM}\right.$, American Radiolabeled Chemicals) was added to three $0.5-\mathrm{ml}$ aliquots of homogenate and allowed to incubate at $37^{\circ} \mathrm{C}$. Reaction was terminated at 0,45 , and 75 min with $40 \%$ TCA followed by centrifugation (45 min, 15,000 g). Rapid and reproducible derivatization for HPLC obtained by carefully mixing $5 \mu \mathrm{l}$ of sample supernatant and $50 \mu \mathrm{l}$ of standard $(100 \mu \mathrm{M}$ arginine, citrulline, ornithine, and agmatine in potassium borate buffer, $\mathrm{pH} 9.4$ ) with $45 \mu \mathrm{l}$ of $O$-phthalaldehyde/mercapto-ethanol reagent (Sigma Chemical Co.). After 1 min of reaction, $25 \mu$ l of the mixture was injected manually.

Elution was performed using a Waters reverse phase column maintained at $30^{\circ} \mathrm{C}\left(\right.$ Novapack, $\left.\mathrm{C}_{18}, 3.9 \times 300\right)$ at a flow rate of $1 \mathrm{ml} /$ min. The ratio of solvents A:B:C:D (A = potassium dihydrogen phosphate buffer, $\mathrm{pH}$ 5.96; $\mathrm{B}=$ acetonitrile; $\mathrm{C}=$ water; $\mathrm{D}=$ methanol) used was as follows; 80:8:6:6 isocratic for $5 \mathrm{~min}$ followed by a gradient change to $74: 10: 8: 8$ over $5 \mathrm{~min}$. At $20 \mathrm{~min}$ a gradient change to 0:40: 30:30 occurs over $15 \mathrm{~min}$. After $15 \mathrm{~min}$ of isocratic elution, initial conditions were restored in a gradient over $10 \mathrm{~min}$. Elution fractions were collected at 0.5 -min intervals and prepared for scintillation counting. Absorbance of derivatized compounds was measured at 340 $\mathrm{nm}$, enabling identification of eluate fractions.

Endogenous agmatine levels. We measured endogenous levels of agmatine in plasma and renal cortex tissue using HPLC separation of extracts from control and agmatine treated rats. Lower aorta and vena cava of anesthetized rats (250-gram sibling Frömter-Wistar) 
were exposed by ventral incision. Aminoguanidine $(0.5 \mathrm{cc}, 10 \mathrm{mM}$ in sterile $0.9 \%$ saline) or vehicle was administered as a bolus via the vena cava and allowed to circulate for $5 \mathrm{~min}$. The animals were exsanguinated via the aorta using a syringe containing $0.4 \mathrm{ml}$ heparin and $0.1 \mathrm{ml}$ aminoguanidine ( $1000 \mathrm{U} / \mathrm{ml}$ and $10 \mathrm{mM}$, respectively). Kidneys were rapidly excised, decapsulated and dissected to remove inner and outer medulla. Cortex tissue was then transferred to high speed centrifuge tubes containing cold aminoguanidine $(1 \mathrm{mM}, 1 \mathrm{ml}$ per kidney cortex) in $10 \%$ TCA for homogenization and centrifugation $(1 \mathrm{~h}$, $14,000 \mathrm{~g}$ ). Albumin and large proteins were removed from plasma using $0.5 \mu \mathrm{m}$ and 10,000 mol wt filters (Millipore Corp., Bedford, MA). A partial purification of kidney supernatants and plasma ultrafiltrate was performed by adding $100 \mu \mathrm{l}$ of sample to $900 \mu \mathrm{l}$ of $\mathrm{NH}_{4} \mathrm{OH}(14 \mathrm{~N})$ containing AG 1-X8 ion exchange resin (OH form; Bio-Rad Laboratories, Richmond, CA). The liquid phase was separated from the resin using a syringe with filter attachment $(0.5 \mu \mathrm{m}$; Millipore Corp.). The resin was washed twice more with $1 \mathrm{ml} \mathrm{NH}_{4} \mathrm{OH}$ and the extracts pooled before lyophilization and reconstitution with $100 \mu$ l HPLC grade water.

Because of increased sensitivity obtained by fluorescence detection, samples and pure agmatine standards of known concentration where derivatized using commercially available tagging kit for primary and secondary amino acids (AccQ-Fluor; Waters Corp.) enabling us to measure endogenous levels. Samples were eluted over a reverse phase column maintained at $40^{\circ} \mathrm{C}$ (Novapack, $\mathrm{C}_{18}, 3.9 \times 300$, Waters Corp.) at a flow rate of $1 \mathrm{ml} / \mathrm{min}$. The ratio of solvents A:B:C $(\mathrm{A}=$ Sodium acetate $(138 \mathrm{mM})$ buffer containing EDTA $(3.5 \mu \mathrm{M})$ and TEA ( $6.9 \mathrm{mM})$, pH 5.8 with $\mathrm{H}_{3} \mathrm{PO}_{4} ; \mathrm{B}=$ acetonitrile; $\mathrm{C}=$ water) used was as follows; 100:0:0 isocratic for $1 \mathrm{~min}$ before a step change to 99:1:0 followed by a gradient change to 97:3:0 over $16 \mathrm{~min}$. At $17 \mathrm{~min}$ a gradient change to $94: 6: 0$ occurs over $28 \mathrm{~min}$. After $12 \mathrm{~min}$ of isocratic elution a gradient change to $86: 14: 0$ is complete at $70 \mathrm{~min}$ and maintained for $15 \mathrm{~min}$. At $85 \mathrm{~min}$ a $10 \mathrm{~min}$ gradient change to 82:18:0 commences. A wash cycle consisting of a gradient change to 0:60:40 and a return to 100:0:0 over 30 min followed each run. Fluorescence of derivatized compounds in samples and standards was measured at $250 \mathrm{~nm} \lambda \operatorname{ex} 395 \mathrm{~nm} \lambda \mathrm{em}$, enabling quantification of eluted components.

Micropuncture studies. Studies were performed in Wistar-Frömter rats derived from our colony. These animals express at least 20 glomeruli on the exposed micropuncture surface. Animals were anesthetized (Inactin; $100 \mathrm{mg} / \mathrm{kg}$ ) and prepared for surgery as previously described with catheters in the jugular vein and femoral artery and bladder (25-27). After preliminary surgery the kidney was dissected free from the adrenal gland and perirenal fat via a left subcostal incision. The kidney was placed into a lucite cup and the left ureter cannulated with a PE-50 catheter. The area around the left kidney was then packed and sealed with dilute agar leaving the micropuncture kidney surface exposed. The kidney surface was continuously superfused with warm isotonic $\mathrm{NaCl} / \mathrm{NaHCO}_{3}$ solution. A sustaining infusion of $1.5 \mathrm{ml} / \mathrm{h}$ isotonic saline containing ${ }^{3} \mathrm{H}$ inulin was supplied to deliver $\sim 60-80 \mu \mathrm{Ci} / \mathrm{h}$ for single nephron glomerular filtration rate (SNGFR) and APR measurements. Animals also received littermate plasma infusion ( $1 \% \mathrm{TBW}$ in $60 \mathrm{~min}$ followed by $0.15 \% \mathrm{TBW} / \mathrm{h}$ ) Certain studies were performed in rats which were previously submitted to left unilateral renal denervation as previously described $(26,27)$, 5-7 d before micropuncture studies.

(a) Intracortical infusion of substances. After the animal was prepared for micropuncture, a PE-10 catheter was passed through the capsule of the kidney and the tip located at the cortico-medullary junction for the infusion of a $\mathrm{NaCl}-\mathrm{NaHCO}_{3}$ vehicle infused at a constant rate of $0.6 \mathrm{ml} / \mathrm{h}$ throughout an initial control and experimental periods. In the test group, agmatine $(20 \mathrm{nM} / \mathrm{h})$ was added to the vehicle during the experimental period.

(b) Urinary space infusion of substances. In these experiments we collected late proximal fluid before, during and after the infusion of substances directly into the glomerular capsule. A 5-7- $\mu \mathrm{m}$ tip pipette connected to a Hample nanoliter microperfusion pump was inserted into the urinary space of a superficial glomerulus (28). After localization of the late proximal segment, an oil block was inserted in the last segment and a timed collection was obtained for the assessment of control SNGFR and APR. The pump was then turned on to infuse either vehicle or test substances at a flow of $5 \mathrm{nl} / \mathrm{min}$ in the urinary space (normal SNGFR is $\sim 40 \mathrm{nl} / \mathrm{min}$ ). After $10 \mathrm{~min}$ of infusion a second late proximal tubule sample was collected. Subsequently, the pump was turned off and a final assessment of SNGFR and APR was obtained from a late proximal collection after a 10 min recovery period.

Agmatine was infused at concentrations sufficient to establish $\sim 6 \mu \mathrm{M}, 0.8 \mu \mathrm{M}$ and $0.1 \mu \mathrm{M}$ concentrations in the urinary space. In order to evaluate the role of $\alpha_{2}$ receptors, the $\alpha_{2}$ antagonist yohimbine $(6 \mu \mathrm{M})$ was infused either alone or concurrently with agmatine. We also used the selective $\mathrm{I}_{2}$ receptor agonist BU-224 (Tocris Cookson, Bristol, $\mathrm{UK} ; 1 \mu \mathrm{M}$ ) and the $\mathrm{I}_{1}$ agonist moxonidine (Solvay, Hannover, FRG; $1 \mu \mathrm{M})$.

Clearance and hemodynamic parameters were calculated as previously described (29). Inulin clearance (UV/P) and volumetric measurement of fluid collected from late proximal tubules were employed to calculate SNGFR and APR. Single nephron plasma flow (SNPF) was also determined (25-27) in interstitial infusion studies whereby a micro-adaptation of the Lowry technique (30) was employed to determine the protein concentrations of systemic $\left(\mathrm{C}_{\mathrm{A}}\right)$ and efferent arteriolar $\left(\mathrm{C}_{\mathrm{E}}\right)$ plasma. The determinants of SNPF were; $\mathrm{SNPF}=\left(\mathrm{SNGFR} * \mathrm{C}_{\mathrm{E}} /\left(\mathrm{C}_{\mathrm{E}}-\mathrm{C}_{\mathrm{A}}\right)\right]$. To take best advantage of the paired nature of the experiments, the effects of treatments were analyzed by one-way ANOVA with design for repeated measures as described previously (27).

\section{Results}

ADC activity and location in mammalian tissue. ADC activity was assessed from the production of ${ }^{14} \mathrm{CO}_{2}$ from radiolabeled L-arginine. Table I depicts the decarboxylation of labeled arginine in various organs expressed as $\mathrm{CPM}^{14} \mathrm{CO}_{2}$ generated in 60 min on a whole organ basis and per gram wet tissue. Significant activity was observed in all organs within the mitochondria enriched fraction only, validating the results of $\mathrm{Li}$ et al. (1). Furthermore, we have observed that mammalian ADC is extremely sensitive to freezing and thawing, resulting in a dramatic loss of activity.

Polyclonal antibody immunostaining for DAO. The distribution of diamine oxidase as observed by immunohistochemistry was identical in human and mouse tissues. Diamine oxidase was present in the following locations: the basal level of the skin epidermis, glomeruli, the decidua of the placenta, epithelial cells in the small intestine, blood and tissue eosinophils, macrophages, and smooth muscle cells of veins, arteries, bronchioles, stomach wall, and skin. Diamine oxidase was not present in brain, heart, liver, adrenals, ovary, or skeletal mus-

Table I. ${ }^{14} \mathrm{CO}_{2}$ Generated from Labeled Arginine by Mitochondria Enriched Cell Fraction

\begin{tabular}{lcc}
\hline $\mathrm{CPM}^{14} \mathrm{CO}_{2}$ in $60 \mathrm{~min}$ & Per whole organ & Per gram wet tissue \\
\hline Brain & $1669 \pm 203$ & $1147 \pm 140$ \\
Liver & $3453 \pm 474$ & $238 \pm 33$ \\
Heart & $407 \pm 64$ & $390 \pm 62$ \\
Spleen & $170 \pm 36$ & $266 \pm 56$ \\
Kidney cortex & $2303 \pm 199$ & $1076 \pm 93$ \\
Kidney medulla & $917 \pm 200$ & $2743 \pm 600$ \\
Lung & $94 \pm 24$ & $69 \pm 18$
\end{tabular}




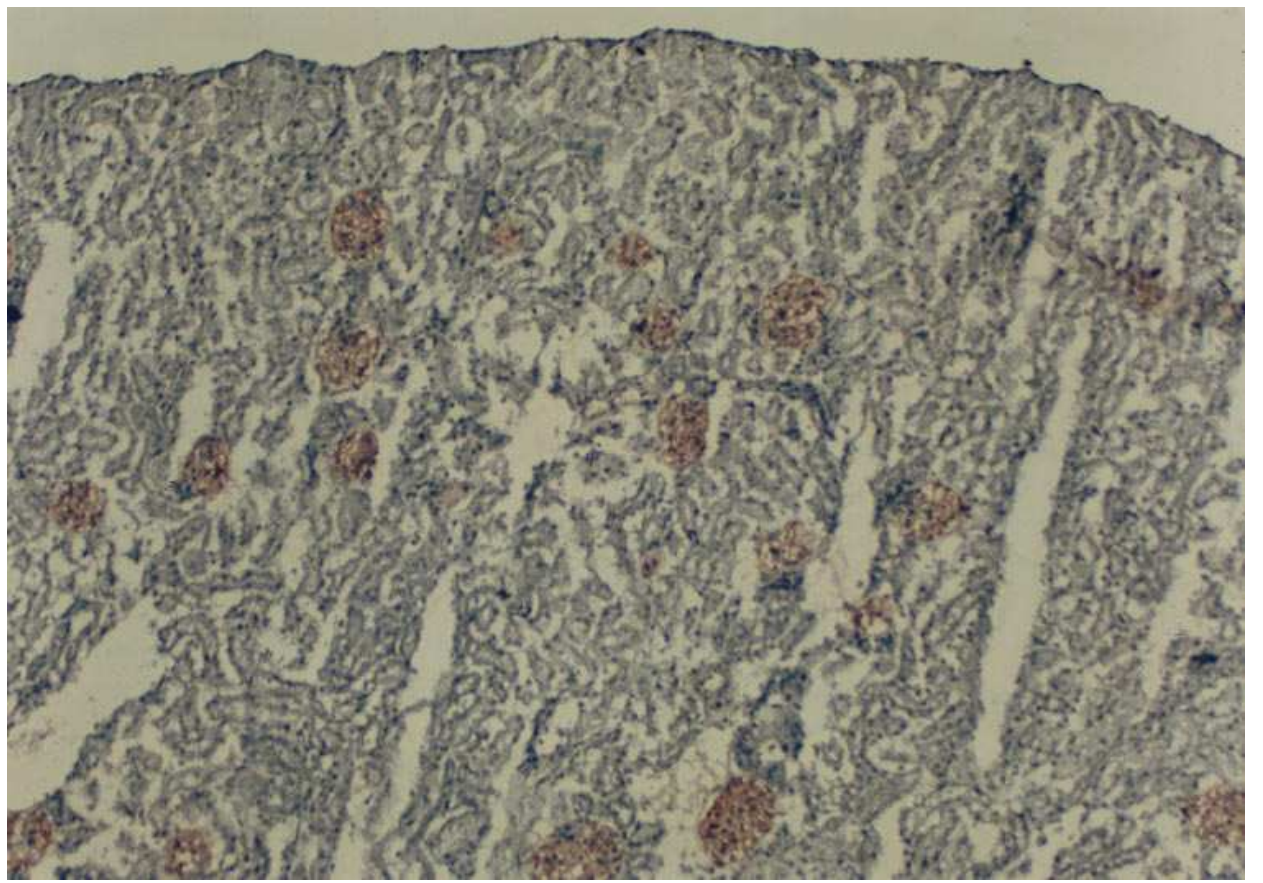

Figure 2. Immunohistochemical location of the enzyme diamine oxidase in the kidney cortex demonstrating the location of diamine oxidase primarily concentrated in glomerular structures. cle. Fig. 2 demonstrates DAO primarily located in glomeruli of rat kidney.

DAO enzyme activity - metabolism of agmatine. A linear relation, $r=0.98$, was established between $\mathrm{H}_{2} \mathrm{O}_{2}$ concentration and fluorescence over the range tested in our preparation. Maximal production of $\mathrm{H}_{2} \mathrm{O}_{2}$ in 60 min was observed with a $K_{\mathrm{m}}$ of $5 \mu \mathrm{M}$ (Fig. 3). $K_{\mathrm{m}}$ for other DAO substrates were $2.12 \times$ $10^{-4} \mathrm{M}$ for putrescine, $1 \times 10^{-3} \mathrm{M}$ for spermine and $1.5 \times$ $10^{-5} \mathrm{M}$ for histamine.

HPLC identification of arginine metabolites. Fig. 4 is a chromatogram showing the detection and separation of a standard solution containing $50 \mu \mathrm{M}$ citrulline, arginine, agmatine

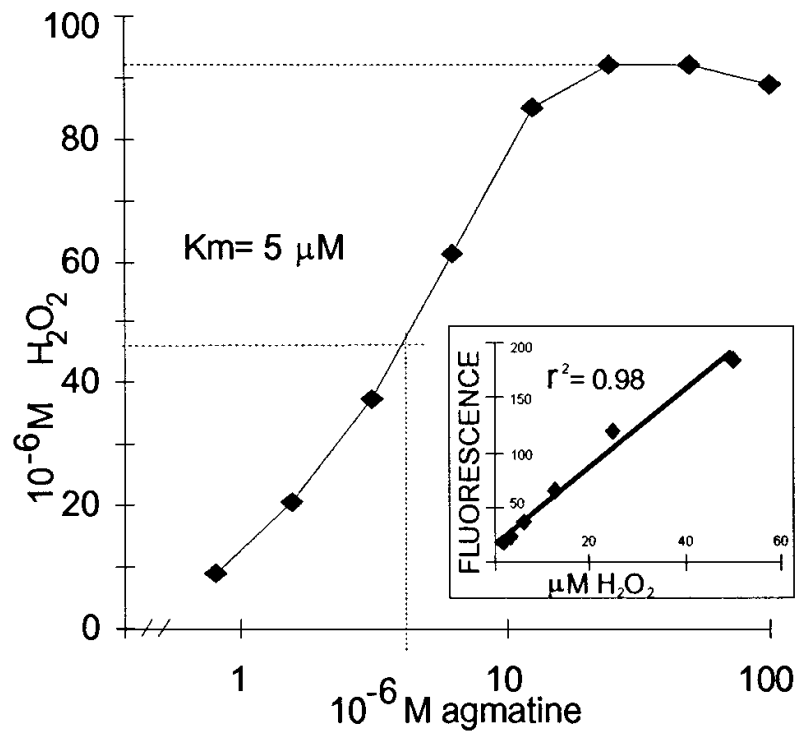

Figure 3. Arginine metabolism by renal DAO generates $\mathrm{H}_{2} \mathrm{O}_{2}$ that can be accurately measured using a peroxidase based assay that generates a fluorophore. Fluorescence is linearly related to concentration over the range of interest. and ornithine. The table in Fig. 4 demonstrates the relative change over time in composition of $\left[{ }^{3} \mathrm{H}\right]$ arginine and ${ }^{3} \mathrm{H}$-metabolites, generated by renal cortical homogenate at $37^{\circ} \mathrm{C}$. In normal kidney, production of labeled agmatine is second only to the conversion of arginine to ornithine and much in excess of the conversion of arginine to citrulline. Only a small amount of other products were present.

HPLC quantification of endogenous agmatine. Using HPLC we have evaluated agmatine levels in kidney and ultrafiltrate of plasma in normal rats and after the in vivo administration of aminoguanidine to acutely block DAO activity. Circulating plasma levels of agmatine were $0.7 \mu \mathrm{M}$ and increased twofold to $1.3 \mu \mathrm{M}$ after DAO inhibition (Table II). Agmatine levels in kidney homogenates in both control and aminoguanidine treated rats were 1.5 and $1.7 \mu \mathrm{M}$, respectively.

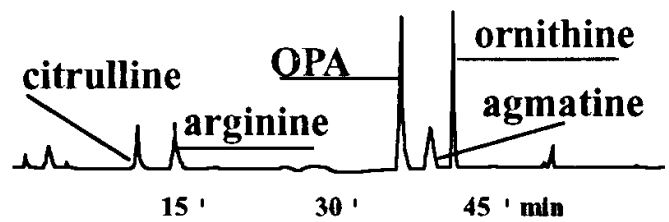

\begin{tabular}{c|l|l|l}
$\begin{array}{c}\text { \% labeled } \\
\text { products }\end{array}$ & $\begin{array}{c}\mathbf{T = 0} \\
\text { min }\end{array}$ & $\begin{array}{c}\mathbf{T = 4 5} \\
\text { min }\end{array}$ & $\begin{array}{c}\mathbf{T = 7 5} \\
\text { min }\end{array}$ \\
\hline citrulline & 0 & 1.7 & 1.8 \\
\hline arginine & 100 & 57.7 & 40.4 \\
\hline $\begin{array}{c}\text { agmatine } \\
\text { ornithine }\end{array}$ & 0 & 12.8 & 18.9 \\
\hline
\end{tabular}

Figure 4. HPLC chromatogram demonstrating separation of OPA derivatized amino acid/polyamine standard $(25 \mathrm{ml}, 50 \mu \mathrm{M})$. The values in the lower part of the figure demonstrate the relative production of labeled arginine metabolites by kidney homogenates. Conversion of arginine to agmatine is second only to the conversion of arginine to ornithine. 
Table II. Endogenous Agmatine in Plasma and Renal Cortex: Effect of Acute Aminoguanidine Treatment

\begin{tabular}{lcc}
\hline \multicolumn{1}{c}{$[\mu \mathrm{M}]$} & Plasma ultrafilrate & Kidney cortex extract \\
\hline Vehicle & 0.7 & 1.5 \\
Aminoguanidine & 1.3 & 1.7
\end{tabular}

Interstitial infusion of agmatine. As seen in Fig. 5, the continuous infusion of control vehicle solution resulted in a modest reduction in nephron filtration rate and absolute proximal reabsorption over the 90 -min period. The decrease in SNGFR was due to reductions in nephron plasma flow $(114 \pm 30$ to $97 \pm 110 \mathrm{nl} / \mathrm{min})(P<0.05)(n=5)$. Interestingly, agmatine infusion at $20 \mathrm{nM} / \mathrm{h}(n=7)$ completely prevented this vehicle associated decrease in SNGFR and APR.

Urinary space infusion of agmatine. Vehicle alone infused into the urinary space did not alter SNGFR and APR over these short time periods $(n=8)$. However, when agmatine $(6 \mu \mathrm{M})$ is infused into the urinary space $(n=12)$, SNGFR and APR increased significantly $(P<0.01)$ (Fig. 6). Values returned to baseline after the infusion was discontinued for a period of $10 \mathrm{~min}$, demonstrating that agmatine effects are reversible. SNGFR and APR also increased in response to $0.8 \mu \mathrm{M}$ agmatine $(n=8)(P<0.05)$, but $0.1 \mu \mathrm{M}$ agmatine microperfusion did not significantly increase SNGFR and APR $(n=13)$ (Fig. 7). Agmatine at $0.8 \mu \mathrm{M}$ increased APR from $8.5 \pm 1.2$ to $12.1 \pm 1.2 \mathrm{nl} / \mathrm{min}(P<0.05)$.

When yohimbine was infused alone $(n=18)$ at a concentration far in excess of its $K_{\mathrm{i}}$ (nM range) there was a negative effect on SNGFR and APR (Fig. 8). This response was not evident during co-infusion with agmatine $(n=11)$.

We then examined the effects of intra-urinary space mi-
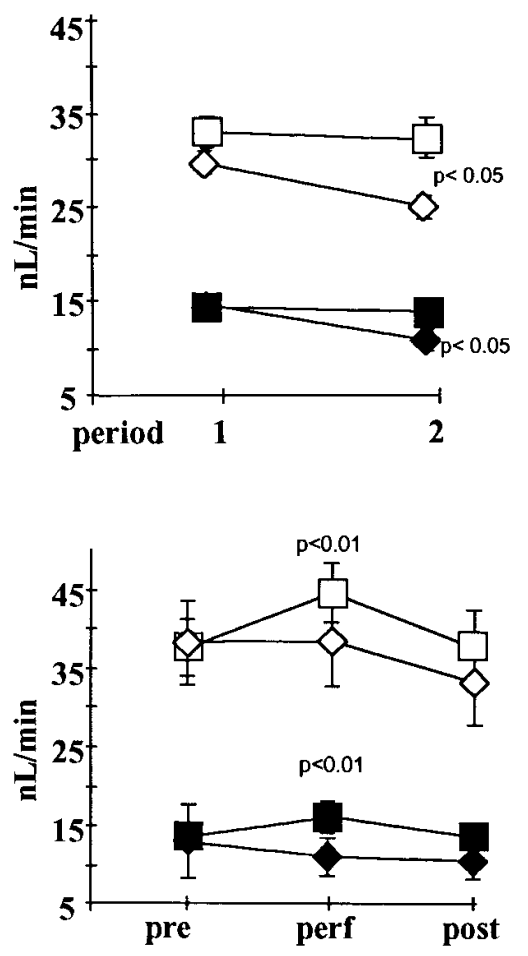

Figure 6. Single nephron function (SNGFR and APR) before during and after pre, perf and post, respectively, urinary space infusion of agmatine $(6 \mu \mathrm{M})$ or vehicle.
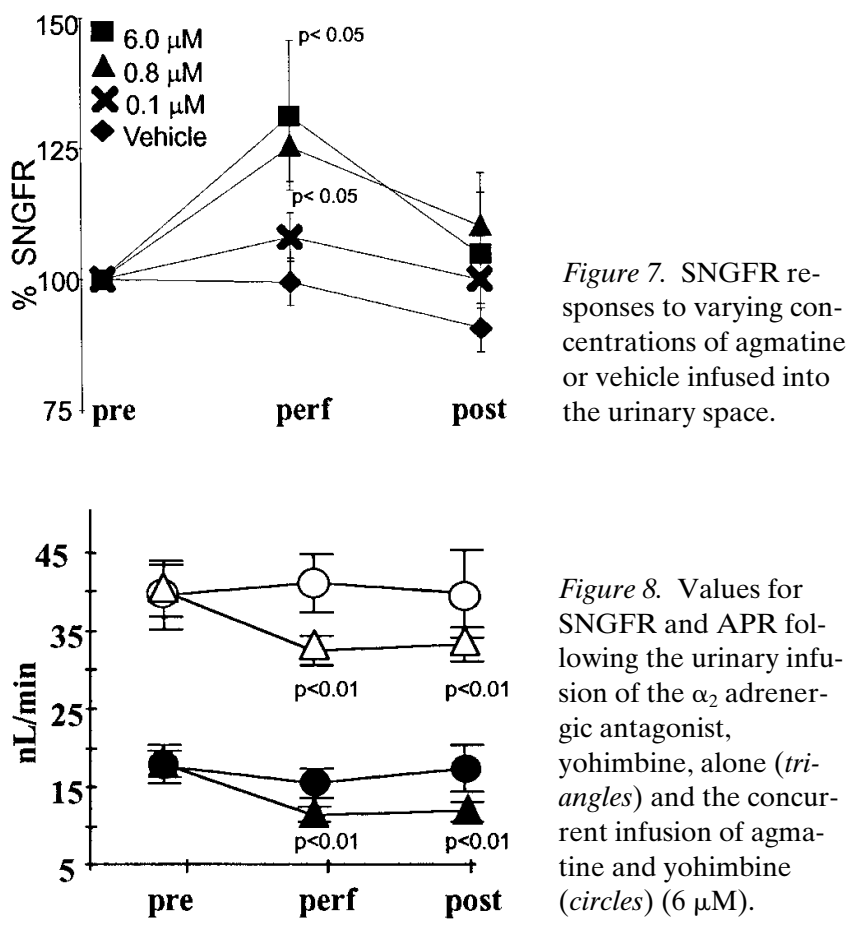

Figure 8. Values for SNGFR and APR following the urinary infusion of the $\alpha_{2}$ adrenergic antagonist, yohimbine, alone (triangles) and the concurrent infusion of agmatine and yohimbine (circles) $(6 \mu \mathrm{M})$.

croperfusion with agmatine $(6 \mu \mathrm{M})$ in previously denervated kidneys in order to assess the role of prejunctional $\alpha_{2}$ adrenoreceptors and the requirement of renal innervation. Agmatine administration increased SNGFR transiently in a fashion nearly identical to findings in innervated kindeys $(n=9)$ (Fig. 9). Interestingly, APR did not increase during agmatine microperfusion in denervated kidneys.

The $\mathrm{I}_{2}$ receptor agonist BU-224 infused into the urinary space produced a significant $(n=9, P<0.05)$ increase in SNGFR (Fig. 10), a response of similar magnitude to that achieved by agmatine. However, the recovery phase differed significantly in that elevated SNGFR persisted after termination of BU-224 infusion. In addition, the $\mathrm{I}_{2}$ agonist did not increase APR, thus glomerulo-tubular balance was not maintained. In contrast, infusion of moxonidine, a selective $\mathrm{I}_{1}$ agonist (31), did not affect SNGFR or APR $(n=7)$.

\section{Discussion}

Assessment of ADC activity and identification by HPLC of agmatine production in the present study confirms recent reports of an alternate pathway for arginine metabolism in mammals (9-11). The heterogenous location of DAO suggests that

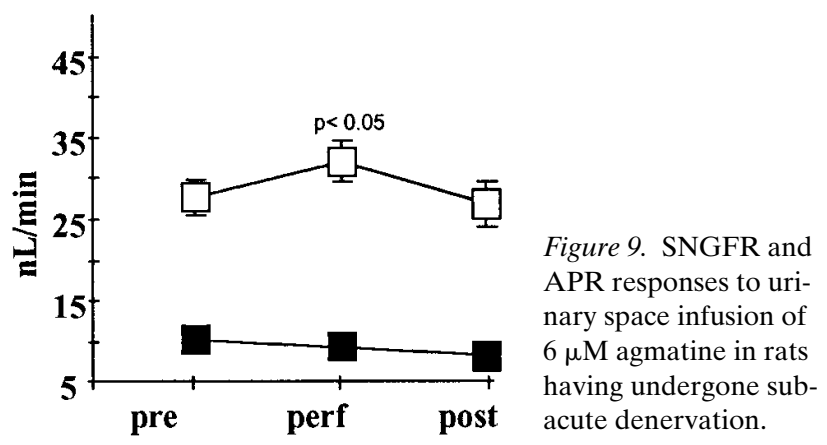




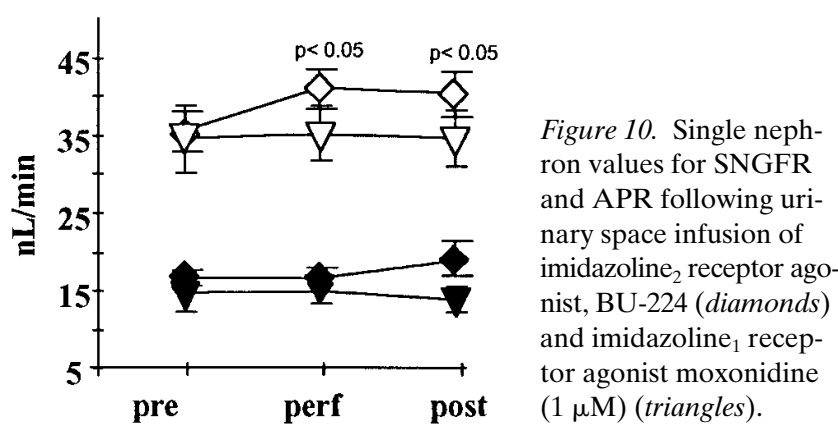

certain tissues or organs may have a capacity to regulate local agmatine levels. In this respect the fact that glomeruli are primary renal sites for DAO may be indicative of local regulation of agmatine levels. We have also demonstrated that agmatine elicited functional responses in the kidney that could involve multiple receptor types and/or sites of action.

${ }^{14} \mathrm{CO}_{2}$ generation from labeled arginine revealed significant ADC activity in the mitochondria enriched fraction of all organs tested (highest in brain, liver and kidney). It should be noted that these values do not indicate the relative enzyme activity among organs since there was no control of cold arginine levels in these preparations. Since arginine levels in kidney are undoubtedly high, these values must underestimate actual ADC activity. The transport of agmatine across the cell membrane has not yet been characterized but must occur since we have demonstrated glomerular effects which can be best explained by transport across proximal tubules into the renal interstitium. HPLC studies clearly demonstrated agmatine production. However, since the metabolic conversion of arginine is a dynamic process involving both synthesis and degradation, the relative amounts of labeled products at 45 and $75 \mathrm{~min}$ do not permit quantification of the relative activity of the various enzymes involved. This is evident in the nonlinear rates of arginine conversion which may reflect exhaustion of rate limiting factors in our assay. A more detailed time course in the presence of varying amounts of cold arginine and inhibitors of enzymes such as DAO will be necessary to clearly delineate relative production rates and product half life.

DAO purified from kidney exhibited a capacity to metabolize agmatine with a $K_{\mathrm{m}}$ of $5 \mu \mathrm{M}$, a value somewhat higher than the concentrations of agmatine required for demonstrating physiologic effects $(0.8 \mu \mathrm{M})$. Endogenous levels of agmatine increased in plasma after aminoguanidine administration suggesting a biologic role for DAO in the metabolism of circulating agmatine (Table II).

Because DAO has been isolated and purified we were able to use immunohistochemistry to describe the distribution of this enzyme. Surprisingly, brain and adrenal tissue contained no diamine oxidase, in spite of the fact that agmatine has been purported to regulate the release of norepinephrine and to act as a nicotinic antagonist $(9,21)$. DAO in renal tissue appears to be primarily located in glomerular structures. The presence of DAO in glomeruli may explain why the effects of agmatine are rapidly reversible while that of the synthetic imidazolinereceptor active compounds are not. Endogenous agmatine levels were also assessed by HPLC in plasma ultrafiltrate $(0.7$ $\mu \mathrm{M})$ and kidney cortical homogenates $(1.5 \mu \mathrm{M})$. Plasma levels increased twofold after DAO inhibition. Questions arise as to the functional role of DAO with respect to normal sites of ac- tion of agmatine and potential effects of the metabolite, guanidino-butylaldehyde. Further studies will be required to establish concentration profiles of endogenous agmatine within glomeruli and other renal structures.

We initially chose to deliver agmatine by interstitial infusion because imidazole type receptors have been localized to the basolateral aspect of proximal tubules (19). This approach succeeded in demonstrating a biological effect since agmatine prevented the decline in SNGFR and APR observed with the infusion of vehicle alone. The effect on tubular reabsorption may be a direct effect of agmatine or indirect via glomerulotubular balance or flow dependent increases in transport rate (28). A direct effect of agmatine on transport rate is supported by recent studies from Morrissey et al. (10) which demonstrated that agmatine stimulates $\mathrm{Na}^{+} / \mathrm{K}^{+}$ATPase in kidney membrane preparations.

To discern tubulo-glomerular feedback induced SNGFR responses from direct effects (and since the interstitial infusion method does not allow for rapid termination of infusion) we opted to infuse agmatine into the urinary space of closed loop nephrons. Substances infused by this technique move directly into the proximal tubule and may be transported into the peritubular interstitium. Since alterations in the flow of tubular fluid to the macula densa was prevented by an oil block, tubuloglomerular feedback responses are eliminated. Agmatine infused in this fashion caused an increase in SNGFR, which is most likely the result of an effect on the glomerulus or associated vasculature. The concurrent increase in APR could have resulted from a direct effect of agmatine or by flow dependent mechanisms. It is also important to note that these functional effects were acutely reversible, implying a short half-life of agmatine in vivo.

We have evaluated the effects of a variety of agmatine concentrations on SNGFR and APR responses. Both 6 and 0.8 $\mu \mathrm{M}$ agmatine concentrations in the urinary space increased both SNGFR and APR, but $0.1 \mu \mathrm{M}$ agmatine failed to influence nephron function. If agmatine in the microperfusion pipette exerted any direct physiologic effects at the glomerulus, these values may slightly underestimate the effective physiologic concentration. Endogenous levels of agmatine in plasma ultrafiltrate and kidney were in the $\mu \mathrm{M}$ range, suggesting that there may be either compartmentalization or significant binding of agmatine in tissue or plasma, thereby reducing bioavailability.

It is of interest that urinary space infusion of the selective $\alpha_{2}$ antagonist yohimbine alone decreases SNGFR and APR. This laboratory has previously shown similar effects of yohimbine in innervated and denervated kidneys (25) suggesting that the endogenous ligands are either blood borne or locally produced. Simultaneous infusion of yohimbine and agmatine produced no change in nephron filtration rate when infused into the urinary space. It is tempting to conclude, based on these data alone, that the effects of agmatine might be exerted via $\alpha_{2}$ adrenergic receptors. However, given the similar responses obtained in denervated kidneys, this conclusion appears unlikely. A recent publication failed to show an agonist or an antagonist effect of agmatine on $\alpha_{2}$ receptors either in brain or smooth muscle, although curiously the authors did demonstrate competitive binding (18). In light of this observation an alternative explanation is that yohimbine decreases SNGFR via the $\alpha_{2}$ adrenergic receptor system while agmatine exerts a positive effect by another mechanism. Based on these data alone, we 
cannot differentiate between potential agmatine action on $\alpha_{2}$ type receptors and a physiologically opposing effect mediated by other mechanisms.

Studies were also performed in rats submitted to left kidney renal denervation. Although these studies were designed to examine the potential interaction of agmatine with renal nerve prejunctional $\alpha_{2}$ adrenoreceptors in eliciting changes in SNGFR and APR, data also allowed us to separate the glomerular and proximal tubular effects of agmatine. Five to seven days after renal denervation, administration of agmatine increased SNGFR by the same degree as in innervated kidneys, precluding an $\alpha_{2}$ prejunctional site of action. However, APR did not increase in response to agmatine in these conditions. The fact that APR did not increase in denervated kidneys, in spite of similar increases in SNGFR, raises at least two possibilities $(a)$ glomerular and tubular effects of agmatine are mediated by different mechanisms and/or possibly receptor types such that APR is dependent on renal innervation, and $(b)$ removal of prejunctional $\alpha_{2}$ adrenoreceptors disrupts glomerulotubular balance thereby eliminating the agamatine associated increase in APR.

The infusion of the $\mathrm{I}_{2}$ receptor agonist BU-224 increased SNGFR by a magnitude similar to that observed with agmatine. However, there were significant and interesting differences between the effects of the $\mathrm{I}_{2}$ agonist and agmatine. Agmatine effects were reversible within 10 min, whereas BU-224 exerted a sustained effect on SNGFR. This finding could be explained by a longer half life of the synthetic compound at its site of action. Another important difference between the effects of urinary space infusion of agmatine and BU-224 was that APR remained unchanged during the infusion period. In light of the fact that imidazole receptors are located on the proximal tubule (19), it is possible that the quantity of $\mathrm{I}_{2}$ agonist utilized $(<1 \mu \mathrm{M})$ may have exerted partial antagonist effects at these receptors and actually prevented a flow dependent increase in APR. Further studies are required which examine the direct effects of agmatine and imidazoline agonists on major transport systems, such as the $\mathrm{Na}^{+} / \mathrm{H}^{+}$antiporter in the proximal tubule.

We cannot discount the possibility that agmatine might also exert effects by non-receptor-dependent mechanisms. Diamines and polyamines have been suggested to exert effects on P and L-type calcium channels (32). Effects on the reloading or release of calcium from $\mathrm{IP}_{3}$ sensitive pools could account for alterations in proximal tubular transport by agmatine. Since arginine decarboxylase and nitric oxide synthase use a common substrate, arginine, it is not unreasonable to speculate that agmatine might exert a modulatory effect on nitric oxide production. Biologic amines do inhibit inducible nitric oxide synthase (33), but effects on the constitutive NOS have not been described. Previous studies from our laboratory have suggested that L-NMMA, by inhibiting constitutive nitric oxide synthase in renal tissue, produces a reduction in proximal reabsorption (34).

We have demonstrated arginine decarboxylase activity and the generation of agmatine in renal tissue as well as endogenous agmatine in both plasma and kidney. The enzyme, DAO, metabolizes agmatine and is located in the kidney, primarily in glomeruli. Infusion of exogenous agmatine increases SNGFR and APR. Data suggest that these effects might involve $I_{2}$ (but not $\mathrm{I}_{1}$ ) imidazoline receptors. Furthermore, opposing effects of agmatine and yohimbine could suggest a functional role for ag- matine as a modulator of $\alpha_{2}$ adrenergic effects, although it is unclear that agmatine acts directly via $\alpha_{2}$ receptors. This alternate arginine metabolic pathway located in the kidney may help clarify some of the many renal physiologic effects of arginine. Further studies are required to delineate the cell systems which are influenced by arginine decarboxylase products as well as the mechanisms and transduction pathways whereby these compounds exert biologic effects.

\section{Acknowledgments}

We acknowledge the valuable discussions with Drs. D. T. O'Connor and J. Videen which helped greatly with this study. The BU-224, the imidazoline $_{2}$ agonist was a gift from Dr. M. Michel, University of Essen, FRG.

These studies were supported by grants from the National Institutes of Health (DK-28602, HL-35018, and HL-48018), funds supplied by the Research Service of the Department of Veterans Affairs. Dr. M. Lortie was supported by fellowships provided by the Fonds de Recherche en Sante du Quebec and the National Kidney Foundation. Dr. V. Vallon was supported by a fellowship grant from the Deutsche Forschungs Gemeinshaft.

\section{References}

1. Reyes, A. A., I. E. Karl, and S. Klahr. 1994. Role of arginine in health and in renal disease. Am. J. Physiol. 267:F331-F346.

2. Ketteler, M., W. A. Border, and N. A. Noble. 1994. Cytokines and L-arginine in renal injury and repair. Am. J. Physiol. 267:F197-F207.

3. Nathan, C., and Q-W Xie. 1994. Nitric oxide synthases: Roles, tolls, and controls. Cell. 78:915-918.

4. Scalabrino, G., E. C. Lorenzin, and M. E. Ferioli. 1991. Polyamines and mammalian hormones Part I: biosynthesis, interconversion and hormone effects. Mol.Cell. Endocrinol. 77:1-35.

5. Scalabrino, G., and E. C. Lorenzini. 1991. Polyamines and mammalian hormones. Part II: paracrine signals and intracellular regulators. Mol. Cell. Endocrinol. 77:37-56.

6. Kierzenbaum, F., J. J. Wirth, P. P. McCann, and A. Sjoeralsnia. 1987. Arginine decarboxylase inhibitors reduce the capacity of trypanosoma cruzi to infect and multiply in mammalian host cells. Proc. Natl. Acad. Sci. USA. 84: 4278-4282.

7. Wu, W. H., and D. R. Morris. 1973. Biosynthetic arginine decarboxylase from Escherichia coli. J. Biol. Chem. 248:1687-1695.

8. Rastogi, R., J. Dulson, and S. J. Rothstein. 1993. Cloning of tomato (lycopesicon esculentum Mill.) arginine decarboxylase gene and its expression during fruit ripening. Plant Physiol. 103:829-834.

9. Li, G., S. Regunathan, C. J. Barrow, J. Esharaghi, R. Cooper, and D. J. Reis. 1994. Agmatine: an endogenous clonidine-displacing substance in the brain. Science (Wash. DC). 263:966-969.

10. Morrissey, J., R. McCracken, S. Ishadoya, and S. Klahr. 1995. Partial cloning and characterization of an arginine decarboxylase in the kidney. Kidney Int. 47:1458-1461.

11. Peterson, O. W., M. Lortie, and R. C. Blantz. 1994. Agmatine (AG) effect on glomerular hemodynamics. J. Am. Soc. Nephrol. 5:609. (Abstr.)

12. Granger, D. L., J. B. Hibbs, Jr., J. R. Perfect, and D. T. Durack. 1990. Metabolic fate of L-arginine in relation to microbiostatic capability of murine macrophages. J. Clin. Invest. 85:264-273.

13. Smith, T. 1979. Spectophotometric method for the estimation of arginine decarboxylase. Anal. Biochem. 92:331-337.

14. Novotny, W. F., O. Chassande, M. Baker, M. Lazdunski, and P. Barbry. 1994. Diamine oxidase is the amiloride-binding protein and is inhibited by amiloride analogues. J. Biol. Chem. 269:9921-9925.

15. Yagihashi, S., M. Kamijo, M. Baba, N. Yagihashi, and K. Nagai. 1992. Effect of aminoguanidine on functional and structural abnormalities in peripheral nerve of STZ-induced diabetic rats. Diabetes. 41:47-52.

16. Edelstein, D., and M. Brownlee. 1992. Mechanistic studies of advanced glycosylation end product inhibition by aminoguanidine. Diabetes. 41:26-29.

17. Severs, W. B., J. W. Gordon, M A. Beaven, and S. Jacobsen. 1970. Some observations on aminoguanidine pharmacology. Pharmacology. 3:201-208.

18. Ernsberger, P., R. Giuliano, R.N. Willette, A. R. Granata, and D. J. Reis. 1988. Hypotensive action of clonidine analogues correlates with binding affinity at imidazole and not $\alpha_{2}$-adrenergic receptors in the rostral ventrolateral medulla. J. Hypertension. 6 (suppl. 4):S554-557.

19. Coupry, I., D. Atlas, R-A. Podevin, I. Uzielli, and A. Parini. 1990. Imidazoline-guanidinium receptive site in renal proximal tubule: Asymmetric dis- 
tribution, regulation by cations and interaction with an endogenous clonidine displacing substance. J. Pharmacol. Exp. Ther. 252:293-299.

20. Sun, M. K., S. Regunathan, and D. J. Reis. 1995. Cardiovascular responses to agmatine, a clonidine displacing substance, in anesthetized rat. Clin. and Exper. Hypertension. 17(1\&2):115-128.

21. Loring, R. H. 1990. Agmatine acts as an antagonist of neuronal nicotinic receptors. J. Pharmacol. 99:207-211.

22. Baylin, S. B. 1990. Histaminase (diamine oxidase) activity in human tumors: an expression of a mature genome. Proc. Natl. Acad. Sci. USA. 87:73477351.

23. Watkins, S. 1991. In situ hybridization and immunohistochemistry. In Current Protocols in Molecular Biology. F.M. Ausubel, R. Brent, R E. Kingston, D.D. Morre, J.G. Seidman, J.A. Smith, and K. Struhl, editors. John Wiley and Sons, New York. 14.0.1-14.6.13.

24. Patchett, M. L., C. R. Monk, R. M. Daniel, and H. W. Morgan. 1988. Determination of agmatine, arginine, citrulline and ornithine by reversed-phase liquid chromotography using automated pre-column derivatization with o-phthalaldehyde. J. Chromatography. 425:269-276.

25. Tucker, B. J., O. W. Peterson, K. Munger, E. Bird, M. Mitchell, J. C. Pelayo, and R.C. Blantz. 1990. Glomerular hemodynamic alterations during renal nerve stimulation in rats on high and low salt diets. Am. J. Physiol. 258:F133F143.

26. Thomson, S. C., B. J. Tucker, F. B. Gabbai, and R. C. Blantz. 1990. Glomerular hemodynamics and alpha- 2 adrenoreceptor stimulation: The role of renal nerves. Am. J. Physiol. 258:F21-F27.
27. Thomson, S. C., F. B. Gabbai, B. J. Tucker, and R. C. Blantz. 1992. Interaction between $\alpha_{2}$-adrenergic and angiotensin II systems in the control of glomerular hemodynamics as assessed by renal micropuncture in the rat. $J$. Clin. Invest. 90:604-611.

28. Peterson, O. W., L. C. Gushwa, and R. C. Blantz. 1986. An analysis of the glomerulo-tubular balance in the rat proximal tubule. Pflugers Arch. 407: 221-227.

29. Blantz, R. C., and B. J. Tucker. 1978. Measurements of glomerular dynamics. In Methods in Pharmacology. M. Martinez-Maldonado, editor. Plenum Publishing Corp., New York. 141-163.

30. Lowry, O. H., N. J. Rosebrough, A. L. Farr, and R. J. Randall. 1951. Protein measurement with the Folin phenol reagent. J. Biol. Chem. 193: 265275 .

31. Ernsberger, P., M. A. Haxhiu, L. M. Graff, L. A. Collins, I. Dreshaj, D. L. Grove, M. E. Graves, S. G. Schafer, and M. O. Christen. 1994. A novel mechanism of action for hypertension control: Moxonidine as a selective $\mathrm{I}_{1}$-imidazoline agonist. Cardiovasc. Drugs Ther. 8:27-41.

32. Scott, R. N., K. G. Sutton, and A. C. Dolphin. 1993. Interactions of polyamines with neuronal ion channels. Trends Neurosci. 16:153-160.

33. Southan, G. J., C. Szabo, and C. Thiemermann. 1994. Inhibition of the induction of nitric oxide synthase by spermine is modulated by aldehyde dehydrogenase. Biochem. Biophys. Res. Commun. 203:1638-1644.

34. De Nicola, L., R. C. Blantz, and F. B. Gabbai. 1992. Nitric oxide and angiotensin II. Glomerular and tubular interaction in the rat. J. Clin. Invest. 89: 1248-1256. 